\title{
La confesión cristiana y su aplicación en la terapia psicoanalista
}

\author{
Christian confession and its application in psychoanalytic therapy
}

SUSANA BRUNO OCHOA

Licenciada en Filosofía por la Facultad de Filosofía y Letras de la BUAP. Actualmente es estudiante del cuarto semestre de la maestría en Filosofía en la línea de filosofía práctica por la BUAP, con el proyecto de tesis: El concepto de Estado en Hegel. Correo electrónico: susanabruno4@gmail.com

\section{Resumen}

En el presente trabajo se analiza el dispositivo de la confesión en Occidente y su aplicación en la terapia psicoanalítica, con el fin de comprender el desarrollo de la subjetividad Moderna, desde el análisis que realiza Foucault en relación con el nacimiento de las ciencias modernas y su fundamentación en el sujeto. Las ciencias modernas han surgido a través del examen de la vida personal de los individuos, desde el inicio de la pastoral cristiana hasta el nacimiento de la psicología moderna, con el psicoanálisis. La confesión se promueve como un proceso de conocimiento sobre el individuo y como un dispositivo disciplinario, al punto que, se ha interiorizado y forma parte del modo de subjetividad actual.

El ethos filosófico de Foucault del presente trabajo pretende llevar a cabo una relectura de las reflexiones de Foucault entorno al psicoanálisis y la confesión cristiana, para así entender ¿Cómo se ha instaurado la confesión en la modernidad? y ¿Cómo a partir de ella puede plantearse el sujeto moderno?

\section{Abstract}

In this work we analyze the dispositive of the confession in the West and its application in a psychoanalytic therapy to understand the development of modern subjectivity, whose analysis was made by Foucault linked to the born of modern sciences and their basis in the subject. Modern sciences have been founded and built by the examination of the personal life of the individuals since the beginning of the Christian pastoral to the modern psychology thanks to the psychoanalysis. The confession is promoted as a process of knowledge about the individual and as a disciplinary dispositive with the result that he has been internalized and became a part of the actual subjectivity. We are going to follow the philosophical Ethos of Foucault pretending to understand: how was the confession introduced in the modernity? And, how can the issue of the modern subject be addressed? With this questions, a releasing of disciplinary power is being raised. 
A partir de dichas preguntas, finalmente, se plantea considerar un punto de liberación del poder disciplinario.

\section{Palabras clave}

Confesión - Psicoanálisis - Terapia moral - Modernidad - Subjetivación Poder - Saber
Keywords

Confession - Psychoanalysis - Moral therapy - Modernity - Subjectivation - Power - Knowledge

“...Lo cierto es que la confesión se convirtió en Occidente en una de las técnicas más altamente valoradas para producir lo verdadero..."

Michel Foucault

\section{Introducción}

Entre 1970 y 1978, Foucault desarrolla su método de investigación genealógico. En estos años sus investigaciones giran en torno al juego de fuerzas entre saber y poder; el autor se pregunta: 1) ¿qué hace posible la aparición de las ciencias sociales? y 2) ¿cuál es la función de las mismas?, para responder estas preguntas Foucault se centra en el análisis de tres temas: el saber (como el conjunto de discursos y juegos de verdad que sostienen el conocimiento de las ciencias humanas y que sujetan al poder a los individuos), el poder (como relaciones de fuerzas, mecanismos y técnicas de dominación) y el ejercicio de poder sobre el cuerpo (disciplinas y modos de subjetivación). A esta época pertenecen los textos del Poder Psiquiátrico, Los Anormales, el primer volumen de la Historia de la Sexualidad, entre otros.

Foucault considera que el "yo" de la modernidad es un constructo, el cual tiene su desarrollo en los siglos XVIII-XIX, desde estos siglos el sujeto es la base en el que se sustenta todo el conocimiento empírico; bajo el dominio de las ciencias del hombre surge el esquema de las ciencias modernas, el ser que vive es la base de la ciencia biológica, el que trabaja funda las ciencia económica y finalmente el que habla es el pilar de las ciencias del lenguaje ${ }^{1}$, en ese sentido el sujeto es la condición de posibilidad del conocimiento en la modernidad.

Foucault afirma que la categoría de sujeto es un invento ${ }^{2}$ moderno, por ello es posible realizar una deconstrucción histórica del sujeto a través del cual se puede explicar las formaciones históricas que hacen posible la aparición de esta categoría como fundamento de las ciencias modernas. En este ensayo se analizará la confesión como

\footnotetext{
${ }^{1}$ Este desarrollo de las ciencias modernas es la base del argumento del texto de Foucault Las palabras y las cosas. (Foucault, 2016)

${ }^{2}$ Una creación moderna.
} 
un mecanismo moderno que configura las subjetividades y por lo tanto, atraviesa el ámbito de la disciplina, el saber y el poder.

Finalmente, en este trabajo se realiza un análisis del traslado de la confesión cristiana hacia la psiquiatría moderna y su importancia en el análisis psicoanalítico, se enfoca particularmente en los casos de histeria analizados por Sigmund Freud. Con ello se tiene por objetivo, delinear la subjetividad moderna en una de sus principales características dentro del saber disciplinario: el sujeto confesante.

Desde la instauración del modelo de la confesión cristiana, la psiquiatría y más adelante el psicoanálisis, encontrarán en ella un método de terapia moral para el alivio de los desórdenes psíquicos.

Foucault en su obra Los Anormales realiza una historia ${ }^{3}$ de la confesión, en ella se destaca cómo fue que se realizó la transferencia de una práctica secular a una práctica de salud mental pública y finalmente el análisis de cómo se instauró dentro del consultorio del psicoanalista para hacer surgir a las ciencias humanas, para develar el inconsciente a través del lenguaje del deseo y del instinto y con ello sujetar a los individuos a una nueva aplicación del poder.

El psicoanálisis de Sigmund Freud tiene como centro el análisis de una nueva figura de la anormalidad, la cual es la mujer histérica de finales del siglo XIX, también se relacionan los temas del deseo y del instinto temas estudiados por la psiquiatría hacia los años de 1830; el método de la curación por la palabra es el que instaurara de una vez y para siempre la terapéutica de la confesión como modo de sujeción al poder disciplinario de los individuos.

\section{La confesión en el ámbito cristiano y su desplazamiento hacia la psiquiatría moderna}

La pastoral cristiana hace surgir la figura del pastor, el cual es el guía de la comunidad cristiana en general; sin embargo también es el elegido, es decir, es el único capaz de ofrecer la salvación de cada uno de los individuos, ${ }^{4}$ y de toda la comunidad: "El pastor es el que vela. "Vela" en el sentido, claro está, de vigilancia del mal que puede hacerse, pero sobre todo de las desventuras que pueden sobrevenir. El pastor velará por el rebaño y apartará el infortunio que pueda amenazar al más mínimo de sus animales" (Foucault, 2006:156). Así el pastor además de ser guía, es el puente de comunicación con lo divino, a pesar de ello, la confesión de los pecados no es monopolizada por la figura del pastor, ya que los miembros de la comunidad pueden confesarse entre sí y lograr la expiación. ${ }^{5}$

\footnotetext{
${ }^{3}$ Se podría decir con mayor precisión una genealogía.

${ }^{4}$ Este juego entre colectividad/individualidad del pastorado y la salvación a manos del pastor es lo que permite instaurar los sacramentos (entre ellos la confesión) en la estructura del cristianismo.

${ }^{5}$ En los inicios del cristianismo la confesión funciona como un mecanismo que a través del arrepentimiento y el remordimiento con lleva a la expiación de las culpas; por lo tanto bastaba con confesarse con cualquier miembro de la comunidad cristiana para lograr el cometido que es ser perdonado por los pecados cometidos.
} 
El poder pastoral cristiano se debe su nombre precisamente a la actividad pastoral, que predomina en la comunidad cristiana, al menos hasta el siglo $X^{6}$, la pastoral ejerce una dinámica de reunión/separación de los individuos por un lado, reúne a todos los miembros bajo la figura del pastor y por el otro, distingue a cada uno de los integrantes a través del análisis minucioso de las almas de cada uno de los miembros de la comunidad, pues para que el pastor conozca a los individuos es necesario instaurar como mecanismo la confesión.

La confesión se establece como una de las principales características de la pastoral cristiana y aparece desde los inicios de ella, aunque queda establecido como práctica necesaria en el concilio de Letrán ${ }^{7}$ lo cierto es que desde los orígenes de la pastoral cristiana la confesión fue una pieza importante en la adhesión de la comunidad religiosa y de la absolución de la culpa. Una vez instituida la confesión formalmente en la comunidad religiosa se convertirá en un sacramento fundamental, como parte de una serie de mandatos que se inscribirán dentro de la ceremonia religiosa y que a la vez sustentan el poder de la figura del guía espiritual, así la confesión abierta y difusa en los albores de la comunidad cristiana es monopolizada por la figura del sacerdote. La confesión en los inicios del cristianismo estaba delimitada a aquellos actos de índole sexual, sin embargo a partir del siglo XII se establece como necesaria la penitencia ritual, así la confesión debe ser una calca del alma del confesante, no sólo se confesará los actos, sino los deseos y los pensamientos impuros. ${ }^{8}$ Por lo que la sexualidad es aquello que es digno de investigación y escrutiño, ya no sólo del sacerdote, sino del educador, del psiquatra e incluso del sistema penal.

Si el poder pastoral se centra en conocer a cada uno de los individuos e imponer la ley sobre la vida de estos, el poder disciplinario de la psiquiatría moderna no se conforma con conocer los más intimos deseos de sus pacientes y alinearlos a la ley, sino que ejerce control sobre el cuerpo, lo domina, lo educa y lo adiestra, es decir, lo normaliza. Así, la confesión será un mecanismo primario para la cura. Se pasa del pecado a la enfermedad, sin embargo, se mantiene la estructura de una falta e incluso en el saber médico la confesión remitirá a una terapia moral, tal como en el cristianismo la confesión deriva en una penitencia.

Surge entonces un sincretismo en la figura del padre que, además de ser el encargado de encaminar a las ovejas perdidas del rebaño, siendo un rasgo pastoral que se entremezcla con el deber sanar la espiritualidad del penitente que carga consigo la conciencia de haber incurrido en una falta, lo que produce una mella en el alma, un malestar de la espiritualidad que no le permite hallar la paz consigo mismo, esta falta ha de ser "curada" por el padre, cuya función es doble como lo señala Jean Delumeau: "Su bienestar psíquico,su vida de relaciones, sus comportamientos cotidianos podian ser modificados por las exigencias más o menos grandes de aquel

\footnotetext{
${ }^{6}$ Siglos en los cuales la estructura del poder pastoral entra en crisis y surgimiento de la disciplina en otras instancias, a saber, la familia y la escuela entre otras.

${ }^{7}$ Convocado por el papa Calixto II en 1123, entre otras cosas prohibía el matrimonio a los sacerdotes y establece la confesión como obligatoria.

${ }^{8}$ La confesión, a partir de este momento será exhaustiva se deberá relatar detalladamente todo lo que se relacione con los deseos y el placer, aquello que Foucault denomina la voluptuosidad del cuerpo.
} 
que la Iglesia le asignaba a un tiempo como padre como médico y como juez" (Delumeau,1990:16)

La confesión entonces, es tomada como modelo de disciplina y control de los sujetos,

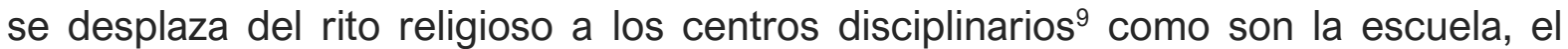
hospital y el sistema penitenciario. En estos recintos ya no basta con confesarse si no que es necesario generar un registro que particularice a los individuos que no se adecuan a las normas impuestas con ello tiene su origen el archivo, la ficha y el expediente. El comportamiento ha de verse modificado de diversas maneras, al grado de severidad variará de acuerdo al grado de la falta y del juez.

Foucault considera que la confesión es "[...]un avatar, el avatar de un procedimiento que no es en absoluto de censura, represión o hipocresía, sino un procedimiento muy positivo, que es el de la confesión forzosa y obligatoria [...] En Occidente la sexualidad es lo que estamos obligados a confesar" (Foucault, 2000: 159)

La confesión debido a una moral relacionada con la sexualidad es un tema grave y de suma importancia que ya afectaba a la manera de confesarse, que se debe a la pena o por el grado de intimidad que representa externar algo tan íntimo que subyace en el alma del hombre. Los contrastes que dejaban ver los principios de la histeria se presentaban desde la era que la confesión se ejercía en las iglesias y que "paralizaba" el actuar de los sujetos al intentar hablar de ella, siendo de particular objetivo de este tipo de delitos las mujeres. Se entrevé que la histeria es un problema que se construyó en simultaneo con la cultura de la confesión: "Los observadores de antaño notaron también que la vergüenza, causa de tantos tormentos de conciencia, se manifestaba sobre todo con motivos de pecados sexuales y paralizaba particularmente a las mujeres". (Delumeau,1990:23)

Con el nacimiento de las ciencias del hombre la confesión va a dejar el ámbito religioso para instaurarse dentro de los mecanismos de los discursos verdaderos, se traslada de la confesión con un individuo que se impone como la autoridad espiritual que castiga y orienta a la curación al médico cuyo atención se centra en la curación mediante el reconocimiento de que el paciente se encuentra en una idea errónea y con ellos se hallará la cura: "Tales consejos serán repetidos hasta luego de la edad por todos los directores de la conciencia que se preocupen del bienestar psicológico de los penitentemente obligados a auto curarse". (Delumeau, 1990:32)

La senda que marcó la confesión cristiana será que seguirán las ciencias de la psique, ya que, los datos serán obtenidos mediante los procesos de verbalización individual, por ello las ciencias disciplinarias hacen de la confesión la piedra angular para la producción del saber y no sólo eso sino que se inscribe en el centro de los procedimientos del poder: "La confesión de la verdad se inscribió en el corazón de los procedimientos de individualización por parte del poder [...]" (Foucault, 2005:65) La confesión, entonces, deja de pertenecer al sigilio de la comunidad, al rito religioso y se instaura como método de verdad y mecanismo de saber y forma de sujección al

\footnotetext{
${ }^{9}$ El confesionario ya tiene tintes de una estructura disciplinaria, tal como lo resalta Foucault, ya que, al ser un examen del alma no hace otra cosa sino que acoger nuevamente al sujeto que estaba en pecado y por lo tanto participaba en un tipo de exclusión por la comunidad
} 
poder; entre las disciplinas que aprovechan está larga historia de Occidente de una forma de individualidad: el sujeto confesante se encuentra la psiquiatría moderna.

Previamente a tratar el tema de la confesión en el saber médico psiquiatrico, es importante comprender la transición que se da en relación con la consideración clásica de la locura y de ésta en el inicio de las ciencias modernas; este cambio es destacable ya que, con ello se podrá comprender porque la confesión es un método bastante eficaz para la disciplina en la estructura del poder. ${ }^{10}$

Una de las diferencias que suceden duante la transición entre el rito pastoral y la confesión psiquiatrica es que en el primero se establece el dialogo como herramienta fundamental para la confesión, pues gracias a esta, el sujeto se compromete a recorrer el camino de la penitencia en conjunto con el pastor, es entonces cuando se logra una apertura donde ambos se encuentran en el mismo nivel:

"Si se confiesa alguna falta grave a un pariente o a un amigo que se ha elegido, es ante todo porque uno está seguro de su cariño (...) porque el intercambio será reciproco, porque cada uno será trasparente ante el otro y ambos compañeros de diálogo se hallarán en pie de igualdad de planos". (Delumeau,1990:34)

Esta técnica usada durante el rito es diferida por la confesión psiquitrica, donde sólo se enfoca al paciente a hallarse en un plano de equivoco.

En el texto Poder Psiquiátrico, Foucault afirma que hay un desplazamiento de la locura con relación a la conceptualización de ésta en la época clásica en vinculación con el nacimiento de la ciencia psiquiátrica moderna: Hasta el siglo XVIII, ya que atribuirle locura a alguien era decir que se engañaba, lo que caracterizaba al loco era el sistema de creencia. A partir del siglo XIX, el elemento, por el cual, se atribuye la locura es la insurrección de la fuerza, la locura se representa un desencadenamiento de una fuerza indomable. (Foucault, 2007:24). Este desplazamiento de la concepción de la locura es de suma importancia, ya que, desde éste es posible comprender cómo se instaurarán una serie de técnicas y mecanismos disciplinarios, entre ellos la confesión para conseguir la cura a tráves de un tratamiento moral. ${ }^{11}$

En el Poder psiquiátrico Foucault analiza una serie de casos que culminan en lo que se denominan "escenas de curaciones", de estas escenas el autor abstrae una serie de características generales que le permitirán considerar a la confesión como elemento importante para el tratamiento, la curación y para las exhortaciones morales orientadas a una dirección general que será la disciplina. ${ }^{12}$

De las características de las escenas de curación Foucault resalta las siguientes: "[...]1) No hay reconocimiento de las causas de la enfermedad. 2) No se trata de aplicar una receta técnica médica se trata del enfrentamiento de dos voluntades, es decir, se reconoce como batalla y relación de fuerza determinada. 3) Existe el

10 Foucault recalca que después de la confesión del alienado, que se relaciona con un relato autobiográfico, no se aplica ningún tratamiento médico en específico, sino que todo se reduce a una aplicación de la fuerza la cual desemboca en lo que podríamos en una segunda confesión del paciente acerca de estar en un error y es esto lo que afianza la curación. Esta práctica no es la aplicación de un saber médico sino la aplicación de una fuerza desnuda.

${ }^{11}$ Si la locura se entiende como un desbordamiento de la fuerza, es necesario que sea controlada, canalizada y sujetada, esto sólo se logra a través de la disciplina y de la dosis necesaria de violencia.

${ }^{12}$ Existe un segundo desplazamiento en el siglo XIX, del poder soberano al poder disciplinario. 
enfrentamiento de dos fuerzas en el enfermo: conflicto entre la idea fija a la cual él se ha aferrado y el temor al castigo. Todo debe acabar con una victoria. 4) El enfermo reconoce que su creencia era errónea y delirante y 5) La verdad es alcanzada a través de la confesión y no del saber médico, con la confesión se sella el proceso de curación." (Foucault, 2007: 27)

En este esbozo de las escenas de curación resaltan dos elementos importantes: el primero es el enfrentamiento de fuerzas, la del médico y la del enfermo; pero también la de la verdad que se impone sobre las ideas erróneas de los pacientes. La confesión sólo es admisible si se da dentro de los marcos de la disciplina, sólo si responde a la aceptación del enfermo de cierto error sobre, el cual, se había instaurado una serie de fantasías y vacilaciones inaceptables en la vida social. ${ }^{13}$ En ese sentido la confesión queda establecida como método de curación, pero también se instaura en ella un discurso de verdad, el cual, no es el de la ciencia, por supuesto, es la verdad que enuncia el paciente.

Ahora bien, una vez comprendida la paulatina instalación de la confesión en Occidente, en un inicio la confesión era algo propio de las comunidades cristianas y se reducía al ámbito de las prácticas sexuales, después surge el rito de la confesión y la figura del padre como aquél que puede confesar, en este punto la confesión será obligatoria y ampliaría su dominio sobre los sujetos, ya que, no sólo versará sobre las prácticas sexuales, sino también se filtrará dentro del ámbito de los deseos y de las satisfacción de los sentidos, finalmente la confesión se instaura en la práctica psiquiátrica y queda en manos del médico; así surge en un fenómeno interesante que dará pie a la práctica psicoanalítica que es el nacimiento dentro de la clínica de la autobiografía.

En la Clase del 19 de diciembre de 1973 Foucault expone el caso clínico del señor Dupré llevado por el médico Lauret, aquí no sólo se le pide al enfermo que acepte su condición, sino que escriba su biografía desde los detalles escolares hasta su paso por las instituciones psiquiátricas; así la confesión entra en el campo del lenguaje como enunciado de verdad.

En el caso del señor Dupré se describe un paciente que desconoce la autoridad hasta el punto de considerar que en el asilo él es el único hombre, no le concede ningún valor al dinero, puede hablar con los osos y pertenece a una de las tres familias que por su nobleza predominan en la Tierra, al punto de considerarse él mismo Napoleón. (Foucault, 2007: 172). Más adelante, aparece la escena de curación, entre otras cosas se le deja ver la importancia del dinero, de la higiene y de los buenos modales; sin embargo lo que resalta en el texto son tres cosas: 1) el médico Lauret se presenta ante el señor Dupré como una figura de autoridad que desaprueba el comportamiento del alienado, 2) el médico logra la confesión del paciente de que aquello que cree real es producto de la fantasía y de la imaginación; sin embargo, esta confesión no se logra

\footnotetext{
${ }^{13}$ La confesión implica aceptar una falta, Foucault considera que desde la pastoral cristiana y hasta el psicoanálisis se mantendrá la idea poco cuestionada de que el penitente o enfermo se encuentra bajo el dominio de una falta que sólo a través de la confesión logra su expiación o curación. Así, se mantiene la idea que detrás de la locura se esconde cierta maldad.
} 
a través de un procedimiento médico sino por medio del uso de la fuerza ${ }^{14}$ y 3 ) para probar su curación Lauret exige al señor Dupré que escriba su autobiografía.

El logro del poder disciplinario dentro del psiquiátrico es hacer de los sujetos partícipes de la curación, a través, de la confesión y del relato autobiográfico, en el cual, el individuo reconoce que ha estado instalado en ideas erróneas; pero sobre todo se instala y se sujeta a las estructuras de poder reconociendo la autoridad. La psiquiatría del siglo XIX no tiene una teoría médica que avale la terapéutica; pero lo que sí existe es una táctica y estrategia del orden disciplinario. A través de la práctica autobiográfica el individuo se reconoce a sí mismo y afirma su identidad, con ello se instala dentro de las estructuras sociales y del poder de las instituciones. ${ }^{15}$

\section{La confesión como la herramienta del psicoanálisis}

Para Foucault el psicoanálisis es un ejercicio del poder, ya que, tiene una función normativa que responde a la rebeldía del enfermo a sujetarse a las normas sociales y una función incorporativa, pues la cura debe significar la reinserción del enfermo en la sociedad. Así, el psicoanálisis ejerce un poder de tipo pastoral, ya que, el psicoanalista ejerce el papel de guía. Por ello, las ciencias psi son normalizadoras, por tanto, son ciencias disciplinarias: "La medida del psicoanálisis envuelve a la locura en un «complejo parental» y encuentra en la confesión de culpabilidad en las figuras de auto-castigo que resultan de Edipo, el psicoanálisis no innova, sino que concluye lo que había empezado la psiquiatría del siglo XIX" (Deleuze y Guattari, 1972:54)

La figura de Freud inicia la psicología, el psicoanálisis se concibe como una estructura del lenguaje, este es la manifestación del inconsciente; con Freud se materializa el poder del médico el único capaz de castigar, el tratamiento médico se complementa con el tratamiento moral.

El conocimiento que surge, a partir, del psicoanálisis y de la confesión produce un saber antropológico y un saber de las ciencias humanas, el saber se hace posible a través del dispositivo de la confesión y de la parresía. ${ }^{16}$

Freud libera al enfermo del asilo; pero lo encadena en una realización de poder más eficaz, porque está disfrazada como un proceso de normalización, la historia individual representa el hilo conductor de la terapia psicoanalítica. El psicoanálisis es un método catártico, Freud considera que la represión de las pulsiones sexuales deriva en las enfermedades nerviosas modernas, por ello, existe una incitación a hablar de la sexualidad; sin embargo, el médico impone formas, normas, reglas y espacios para hablar de la sexualidad.

\footnotetext{
${ }^{14}$ Dupré confiesa la verdad sobre él mismo (nombre, profesión, año de nacimiento...) bajo la ducha, que Lauret le impuso como castigo. Foucault afirma que las circunstancias en las que el paciente ha confesado son secundarias, lo importante es la enunciación la confesión de la verdad es lo que sella el proceso de curación.

${ }^{15}$ Incluso en el poder judicial el proceso penal tiene como base una serie de estrategias que se realizan en torno al sujeto para lograr la confesión de sus crímenes: "La ceremonia penal, con tal de que cada uno de sus actores represente bien su papel, tiene la eficacia de una prolongada confesión pública". (Foucault, 2003: 43)

${ }^{16}$ La parresía es el coraje de hablar con la verdad
} 
En su obra Freud Estudios sobre la histeria, la confesión forma parte importante en la cura de las pacientes, la tesis central en la teoría psicoanalítica es que la neurosis, la psicosis y la histeria son provocadas por los deseos reprimidos que necesitan ser exteriorizados por medio de la palabra: En el caso analizado por Freud de la señorita Elizabeth ${ }^{17}$, quien padecía dolores agudos en la cintura y una pierna, Freud descubre que al tocar el tema de su enamoramiento en relación con su cuñado, la paciente rehúye y sufre de dolores punzantes en la pierna, los cuales, desaparecen una vez que cuenta el episodio; así el médico utiliza este dolor para guiar el interrogatorio hacia donde él considera que desemboca el centro de la aparición de los síntomas histéricos "[...]Poco a poco aprendí a utilizar como brújula ese dolor despertado; cuando ella enmudecía, pero todavía acusaba dolores, yo sabía que no lo había dicho todo y la instaba a continuar la confesión hasta que el dolor fuera removido por la palabra [wegsprechen]. Sólo entonces le despertaba un nuevo recuerdo" (Freud,1992: 163)

En este caso el médico no utiliza una conceptualización universal para llevar a cabo la curación, todo está inscrito en el ámbito del juego de verdad de la paciente, es su enunciación su relato, es decir, su historia personal la que asume todo el protagonismo en la terapia; el psicoanalista se limita a escuchar y a generar relaciones semánticas entre lo simbólico y lo real; en un juego entre ocultar y mostrar la verdad aparece develada; sin embargo la enunciación verdadera no está en manos del médico sino que la posee la paciente. Una vez más existe esta relación parresíaconfesión; si la verdad aparece en un momento velada, después se muestra en toda su realidad esto implica cierto valor para afrontarla a través del proceso de confesión. Sólo mediante lo anterior, puede devenir la curación.

En Tótem y Tabú, Freud realiza un estudio erudito sobre las prohibiciones sexuales a través del tiempo y de las diversas culturas, ya que, el discurso psicoanalítico tiene como supuesto el discurso, e intenta fundar el sujeto por la sexualidad, entonces se concede una primacía a la sexualidad, la ley se contrapone al deseo, pues, el deseo sólo aparece con la prohibición. De hecho, Edipo se presenta como una equiparación simbólica del inconsciente, al ser el ejemplo por excelencia de la realización del deseo prohibido. Analizando las culturas primitivas Freud descubre que a través del totemismo se configuran reglas primitivas relacionadas con la sexualidad entre ellas el incesto y la prohibición al parricidio: "Si el animal totémico es el padre, los dos principales mandamientos del totemismo, los dos preceptos-tabú que constituyen su núcleo, el de no matar al tótem y no usar sexualmente a ninguna mujer que pertenezca a él, coinciden por su contenido con los dos crímenes de Edipo, quien mató a su padre y tomó por mujer a su madre, y con los dos deseos primordiales del niño, cuya represión insuficiente o cuyo nuevo despertar constituye quizás el núcleo de todas las psiconeurosis" (Freud, 1991:134)

La lectura de todas estas ceremonias relacionadas con el totemismo primitivo es la interiorización inconsciente de la regla sociales de los hombres, es evolutiva y se

\footnotetext{
${ }^{17}$ La paciente está renuente a confesar que desde hace tiempo, siente cierta atracción por su cuñado y después de la trágica muerte de su hermana una idea ha invadido su mente: ahora que está sólo ella puede tomarlo por esposo.
} 
integra, se fortalece e incluso se hereda de generación en generación. De hecho, el origen de todas las neurosis es el impulso hacia romper la norma que son coartados. En el caso del pequeño Hans la prohibición de la masturbación y el miedo a la castración sólo pueden ser dilucidados, a través, de la interpretación simbólica de los sueños; para ello es necesario que el propio niño narre los sueños y los asocie con la realidad. ${ }^{18}$ El psicoanálisis plantea ser una ciencia benévola al darle un lugar a los sujetos para hablar de su sexualidad reprimida ${ }^{19}$ y al liberar al alienado de la clínica, lo que, Foucault ha encontrado es una continuidad, se establece una relación de jerarquías de poder entre el médico-paciente y sobre todo el saber médico y el tratamiento no se basa en consideraciones de tipo universal si no en los procesos de individualización y de la información recabada que da origen a los archivos y a los expedientes.

En ambos extractos de los textos de Freud aparece la sexualidad bajo la lupa del psicoanálisis como una teoría o ciencia de la sexualidad, el psicoanálisis con Freud había tomado el estandarte de la liberación sexual; sin embargo, con esta nueva incitación a hablar la sexualidad queda en el foco de atención del poder disciplinario. Foucault duda que el psicoanálisis sea un humanismo, ya que, ha liberado al alienado del asilo pero ha sujetado al individuo a través de la confesión forzándolo a contar una y otra vez los datos más profundos de su alma obligándolo a reconocer su falta, para que el médico pueda expiarlo y reconducirlo al buen camino de la convivencia social. El recorrido crítico que Foucault realiza de la modernidad lo lleva a establecer una línea de continuidad entre el modelo de confesión cristiana y la práctica psicoanalítica, a pesar de sus diferencias, lo cierto es que ambas conforman un espacio de dialogo para que se exprese la experiencia moral y así poder instaurar como estrategia la culpabilidad y la penitencia.

A partir de la lectura que realiza Freud de la tragedia de Edipo se resaltan dos elementos importantes; el primero es la parresía como el valor de hablar con la verdad, se establece como elemento doloroso y necesario para la catarsis y desde un punto de vista de la terapia moral ineludible para la curación; el segundo elemento más importante y que fundará al sujeto en Occidente es considerar que el complejo Edipo $^{20}$ tiene una constitución primigenia, como algo instaurado en el inconsciente de los hombres y se establece de una vez y para siempre la experiencia trágica y desgarradora de la vida del hombre como la contraposición del deseo y la interacción en sociedad. ${ }^{21}$

La confesión por largos siglos en occidente, ha sido uno de los dispositivos principales, productor de la subjetividad del individuo, tal como, es en el presente, el

\footnotetext{
${ }^{18}$ Freud, Sigmund Análisis de la fobia de un niño de cinco años. A propósito de un caso de neurosis obsesiva: Buenos Aires: Siglo XXI, 1909

${ }^{19}$ Lo cierto es que la confesión desde la pastoral cristiana, como se ha visto, no ha reprimido la sexualidad, sino que por el contrario ha existido una incitación a hablar de ésta.

${ }^{20}$ Para efectos de este ensayo lo hemos descrito como insurrección a la doble prohibición básica, presente incluso en las culturas más primigenias, no matar al padre y no tener ninguna relación incestuosa.

${ }^{21}$ Si se quiere ver de la cultura en general, tal como aparece en el texto de Freud La cultura de las masas.
} 
examen de si ha quedado instaurado como un algo permanente, insistente e inagotable para el individuo; el cual, ya no necesita acudir a un confesor; sino que en cualquier instancia de poder disciplinario se encontrará en la necesidad de confesarse haciendo un examen constante de sí mismo, valorando sus conductas en relación con lo moralmente aceptable, confesando sus deseos sexuales esperando la expiación de una culpa instaurada como un dispositivo normalizador.

\section{Conclusión}

La confesión en Occidente ha formado parte importante del proceso de subjetivación de la modernidad, la crítica de Foucault al psicoanálisis es en relación a centrar su teoría en la tesis de que la modernidad se instauró en la represión sexual; cuando de hecho se ha configurado a lo largo de los siglos una incitación hacia la apertura, la divulgación y la confesión de las prácticas y deseos sexuales.

En la modernidad el poder se moldea en un conflicto de fuerzas permanentes entre los cuerpos que están regidos por las disciplinas, a su vez, el poder disciplinario busca ejercer fuerza sobre los cuerpos; pero necesita generar cierto saber para ello debe penetrar en la interioridad de los individuos y develar el alma; ya que, si se conocen los deseos más recónditos del sujeto mayor posibilidad existe de ejercer el poder.

A partir del siglo XVIII, inicia un proceso de medicalización de la sexualidad, con ello los deseos quedan escindidos entre lo normal y lo patológico, la instauración de una moral sana redunda en una sociedad sana, la cual, es apta para el empleo; la nueva fuente de riqueza moderna será la fuerza de trabajo. Por ello la preocupación por el cuidado de la salud; la confesión y la culpabilidad evitarán desviaciones y enfermedades.

Ante este panorama poco alentador, Foucault propone el retorno a las costumbres griegas, el cuidado de sí, ya que es el garante de escapar del poder, a través del cuidado de sí se aspira al arte de la vida, plena, tranquila y armoniosa: "[...]lo que quiere decir Foucault cuando dice que la subjetivación en los griegos constituía la existencia como estética [...] (es) que el arte cualificaba la existencia [...] Pero para que el arte se convierta en la operación de la subjetivación, es preciso que ya no se conforme con construir objetos particulares a los que se llamará obras de arte, es preciso que se convierta es el movimiento de la subjetivación en general, Ahora bien, no es este el caso de la obra de arte[...]" (Deleuze, 2005: 130).

Sin embargo, para que esto sea posible es necesario romper con toda la cadena de poder y dispositivos disciplinarios impuestos, la salida queda, sin duda, a manos de los individuos, de la responsabilidad de vivir siendo fieles consigo mismos. Una invitación socrática que Foucault defiende a lo largo de su obra, si realiza la deconstrucción del pasado es para dilucidar el presente y para superar la situación actual del hombre dominado. Con ello se mantiene en la firme convicción de que la filosofía nos tiene que enseñar a vivir de una manera determinada. 
Perspectivas Revista de Ciencias Sociales - ISSN 2525-1112 | Año 4 No. 7 Enero-Junio 2019, pp. $210-221$

Aceptado: $17 / 06 / 2019$

\section{Bibliografía}

BIRMAN, J. (2007) Foucault y el psicoanálisis. Buenos Aires: Ediciones Nueva Visión. DELEUZE, G. (2005) La subjetivación. Curso sobre Foucault. Argentina: Cactus. DELEUZE, G. y GUATTARI F. (1972) El Anti Edipo. París: Editorial Paidós. DELUMEAU, J. (1992) La confesión y el perdón. Madrid: Editorial Alianza. FOUCAULT, M. (2007) El poder psiquiátrico. Buenos Aires: Fondo de Cultura Económica.

FOUCAULT, M. (2005) Historia de la sexualidad. Vol. I. Voluntad de saber. Buenos Aires: Siglo XXI.

FOUCAULT, M. (2016) Las palabras y las cosas. Madrid: Siglo XXI.

FOUCAULT, M. (2000) Los anormales. Buenos Aires: Fondo de Cultura Económica. FOUCAULT, M. (2006) Seguridad, Territorio y Población. Argentina: Fondo de Cultura Económica.

FOUCAULT, M. (2003) Vigilar y castigar: nacimiento de la prisión. Buenos Aires: Siglo XXI.

FREUD, S. (1992) Estudios sobre histeria. Buenos Aires: Amorrortu Editores. FREUD, S. (1991) Totém y tabú. Buenos Aires: Amorrortu Editores. 